\title{
A Diary Study of Difficulties and Constraints in EFL Learning
}

\author{
HUANG (family name) Jing \\ Foreign Language School, Zhanjiang Teachers University, Guangdong, China \\ English Centre, The University of Hong Kong, Pokfulam Road, Hong Kong, China
}

\begin{abstract}
Drawing on learners' course diaries, this paper explores Chinese EFL learners' perceptions of difficulties and constraints in EFL learning and their responses to the perceived difficulties and constraints. The diary data appear to indicate that the students' learning difficulties lay mainly with their linguistic competence, but a closer scrutiny of the classroom discourse seems to reveal that their linguistic difficulties might be a product of the relationship between their linguistic competence and the demands that examinations placed on it. Students' responses to linguistic difficulties were characterized by predominantly "quantitative" conceptions of, and approaches to, language learning. This quantitative orientation was not generally problematized but deemed functional by students in the examination-oriented context. Socio-psychological constraints raised by diarists included undesirable teacher-learner role relationships, negative self-evaluation, examination anxiety, deficient study skills, and obstacles to independent learning. Although these non-linguistic constraints were not frequently mentioned, it could be argued that socio-psychological factors substantially affected learning. Based on the findings, suggestions are made to aim at informed teaching in the general Chinese EFL university context.
\end{abstract}

Key words: EFL learning; Linguistic difficulties; Socio-psychological constraints; Quantitative/Qualitative conceptions of learning; Quantitative/Qualitative approaches to learning

\section{Introduction}

Learning diaries/journals have been described as important "introspective tools in language research" (Nunan, 1992, p. 118) which can "give us access to the participants' voices” (Bailey and Nunan, 1996, p. 199). Their limitations notwithstanding, diary studies allow us to investigate affective factors, language 
learning strategies, and the learners’ own perceptions of language learning (Bailey, 1991; Bailey and Nunan, 1996). Many diary studies have touched upon dimensions of difficulties and constraints in ESL/EFL learning (e.g. Bailey, 1983; Hilleson, 1996); however, few published studies to date have dealt directly with learner difficulties in EFL settings. The present study intends to explore the nature of Chinese EFL learners’ difficulties by using learners’ course diaries.

Ehrman (1996) has called our attention to the possibility of investigating “difficulties" in second/foreign language learning through research. In the current study, “difficulties” in EFL learning do not refer to disabilities experienced by special learners, but to learning difficulties encountered by normal university students. While "difficulties” refer mainly to dimensions of learning, “constraints” include institutional, socio-psychological and cultural dimensions of obstacles in EFL learning.

In the literature, the broad notion of difficulties/constraints has been examined from various angles. One frequent cause of difficulties in EFL learning is the mismatch between learning style and teaching style (Allwright, 1984; Ehrman, 1996), or the gap between pedagogical agenda and learning process (Nunan, 1995). Another perspective on student difficulties is to think about feelings using a three-element framework of attitudes related to the learning event: motivation, self-efficacy (self-esteem) and anxiety (Ehrman, 1996). These three concepts are closely linked and are all potential sources of EFL learning difficulties. For example, 
Ehrman (1996) emphasizes two kinds of motivation in EFL learning: intrinsic and extrinsic. Intrinsic motivation is very powerful in triggering deep learning while extrinsic motivation without intrinsic motivation is likely to lead to surface learning. Surface approaches to learning have been linked to "quantitative” (as opposed to "qualitative”) conceptions of learning and both are associated with learning difficulties (Benson and Lor, 1999; Biggs, 1987, 1992, 1993; Watkins, 1996).

Learning difficulties/constraints are also often concerned with insiders' perceptions of teacher-learner roles and relationships, which are grounded within a certain culture of learning. It is said that the Chinese culture of learning has contributed to students' reticence and passivity (accepting what the teacher says without question) and has encouraged resistance to pedagogical innovation, e.g. communicative language teaching (see Cortazzi and Jin, 1996a, 1996b; Hu, 2002; Jin and Cortazzi, 1998). However, other researchers (e.g. Cheng, 2000; Littlewood, 1999, 2000, 2001; Liu and Littlewood, 1997) argue that cultural attributes should not be used as a convenient explanation for problems arising in ESL/EFL practice, as Chinese students' apparent passivity in the classroom is more likely to be a consequence of students' lack of proficiency, confidence and motivation and the wider socio-educational context (e.g. the examination-oriented educational system, unsuitable methodologies and inadequately trained teachers). These latter arguments seem to indicate two dimensions of learning problems: linguistic difficulties and socio-psychological constraints. 
The literature outlined above provides us with a background to EFL learners' difficulties in general and the socio-psychological constraints that Chinese students may encounter in the Chinese EFL context. However, these insights have rarely originated from enquiries into learners' own beliefs, expectations, attitudes and concerns. If an important part of teachers' responsibilities is to help learners come to terms with difficulties and constraints in EFL learning in order to involve them in more active and autonomous learning, they should first become aware of learners' own perceptions of and attitudes towards EFL learning processes and problems. Bearing this in mind, the present study addresses two questions:

(1) What are learners' perceptions of difficulties and constraints in EFL learning in the Chinese university context?

(2) How do learners respond to the perceived difficulties and constraints in EFL learning?

\section{Classroom context and data source}

The diary entries used in the present study were collected from a metacognition training (MT) project conducted for BA TEFL undergraduates at a local teachers' College in China. The MT project was incorporated into a regular 
one-semester/18-week EFL reading curriculum (Extensive Reading ${ }^{1}$ ) for the second-year English majors in three classes (38 students each). The objective of the integrated MT was to enhance metacognitive awareness in EFL reading and to foster learner autonomy (Wenden, 1991, 1998). The author taught the Extensive Reading course for these three classes and conducted the MT project. At the same time, the students were taking an Intensive Reading ${ }^{2}$ course, not taught by the researcher. Each class had a different teacher for the Intensive Reading course, one of whom was a North American native speaker of English.

As part of the Extensive Reading course requirements, students were asked to write reading reports (summary and critique of what they had read) and to keep a learning journal, recording their conceptualization of EFL reading processes and their reflections on other aspects of EFL learning (e.g. listening, speaking, writing, grammar and vocabulary learning). However, in reviewing the learning diaries, I found that students were more willing to write about their learning difficulties and their immediate concerns (e.g. their worries about the coming TEM-4 ${ }^{3}$ and their attitudes towards the classroom behaviours of teachers, especially the Intensive

\footnotetext{
${ }^{1}$ In Chinese EFL teaching, Extensive Reading aims to enhance reading comprehension, word power and reading speed and to familiarize students with the target language culture (see also Footnote 2).

${ }^{2}$ Intensive Reading is a text-centred, but not a primarily reading course as it integrates all language skills and emphasizes the meaning of words and knowledge of grammar (Cortazzi and Jin, 1996a). Intensive Reading and Extensive Reading occupy respectively 6-8 and 2 teaching hours per week under usual circumstances.

${ }^{3}$ TEM-4 is an important national Test for English Majors (Band 4) to pass in the $4^{\text {th }}$ semester $\left(2^{\text {nd }}\right.$ year) of the 4-year BA degree programme to be qualified later for conferment of the BA degree in our context.
} 
Reading teacher who held primary responsibility for TEM-4) than their conceptualization of learning processes (i.e. metacognitive awareness, which I had expected).

\section{Data sampling and data analysis}

The original data set totaled 352 entries in English by 72 diarists in three classes who were willing to submit their work for our classroom research. After reviewing the whole data set to allow dominant themes to emerge, 28 of the longer and more substantial entries were selected from each class's set of journals for more detailed analysis. Following this procedure, 84 entries by 57 students were analyzed ${ }^{4}$.

To interpret the diary data, I conducted content analysis (Allison, 2002; McDonough and McDonough, 1997), by counting explicit mentions of difficulties and constraints learners perceived that they encountered and then grouping the mentioned themes into categories. In the process of counting and categorizing, some patterns were more easily recognizable than others. For example, the categorization of the speed difficulty in reading/listening was less problematic because diarists either directly mentioned the word "speed" or the adjectives/adverbs "slow/slowly”, or “(listening materials) too fast”. However, identification of some other categories entailed commitment to repeated

\footnotetext{
${ }^{4}$ Copies of all Class X and Class Y diaries were retained after the course, but for logistical reasons only the 28 Class Z entries chosen for closer analysis were kept.
} 
cross-checking. In some cases, categorization required great attention to the diarist's qualitative explanation in the whole entry. This was a weakness in the process of categorization because a diarist might raise a certain theme, but the theme eventually was not counted into a category just because of uncertainties. To enhance data interpretation, insights from classroom observation and informal interviews are also drawn on occasionally.

All the explicitly mentioned difficulties and constraints in the diary sample are presented in terms of frequency/distribution of mention across writers in Appendix-1. For strategies adopted and perceptions of learning processes (taken together as responses to the perceived difficulties and constraints), only the important themes are detailed in terms of frequency/distribution of mention. A wide range of minority themes is grouped as a broad category of "miscellaneous mentions” (see Appendix-2).

\section{Findings}

\subsection{Students' perceptions of difficulties: Linguistic dimensions}

Students of the three classes mostly expressed concerns about linguistic problems. Therefore, I shall first examine students' linguistic difficulties and their responses to them, then, briefly present their views on the non-linguistic, i.e., the 
socio-psychological constraints in the next section. Linguistic and socio-psychological problems were interrelated in some cases. The separate discussion of these dimensions here is for convenience only.

As indicated in Appendix-1, limited vocabulary in reading, listening, speaking and writing was the most widely attested problem (mentioned in $27 \%$ of all entries and by $35 \%$ of all diarists in the sample). The second most frequently mentioned difficulty was related to speed (entries/diarists $=17 \% / 23 \%$ ) in receptive language processing. Students felt that they read too slowly and that the speed of listening practice materials (audio tapes, or VOA and BBC live programmes) was too fast for them to understand the message expressed. Other problems that they encountered were concerned with grammatical structure, listening/reading comprehension (the dilemma between acquiring speed and understanding, inferential processing, and understanding real-life materials), and the deployment of appropriate strategies for a given task ("to read the question first or to read the text first" in reading practice). The following entry was typical in illustrating these basic problems (diary extracts are kept in the original):

\section{Extract 1:}

During my reading, I met a few difficulties. And here are the main three.

First, the speed. Although I have read a lot of article on how to improve reading speed, it seems to do no help. Every time I read, I can only read word by word. If I try to read fast, in phrase by phrase way, I will know nothing after reading. It is really terrible, I don't know how to deal with the problem.

The second, complicated sentence. Sometimes, the sentences are really too difficult to understand by reading at normal speed. In order to understand, I have to slow down. In this way, 
I can't finish the required work in the given time. How can I manage complicated sentence? I am puzzled.

The third, new words. Some articles have too many new word. It is almost impossible to catch the main idea. Under such circumstance, it is impossible to finish the answers correctly.

This extract also demonstrates the interplay of several difficulties in language processing, e.g., complicated sentence structure, reading comprehension, strategy deployment and reading speed. Students' preoccupation with speed in both reading and listening had its root in the national syllabus for the English majors, skill-based textbooks and the classroom instruction. For example, the Extensive Reading course encouraged skimming, scanning and timed reading of brief texts (Cortazzi and Jin, 1996a, p. 67). This problem became more predominant when they treated "each exercise as taking an exam" (focusing on the correctness/product rather than on the meaning/process). Students were usually made aware that TEM-4 emphasized speed in both listening and reading components. Therefore, in and out of class, they had opportunities to use various practice materials, including TOEFL papers to increase their speed and to aim at a high percentage of correct choices by doing a large amount of multiple-choice exercises. In many cases, reading and listening problems were intertwined with each other:

\section{Extract 2:}

When I do TOEFL listening, I have to frequently stop the tape from going. Because I can not read the answer choices quickly, nor can I decide which to choose within the interval between two questions. The correct answer has the same meaning with what is read in the tape, but it is expressed in a different way. Some other answer choices sometimes seem right but in fact they are wrong. I have to read carefully in order to avoid choosing the wrong answer. However, time does not wait for me. Why my problems always concern with speed? I'm too slow in reaction, maybe, I should have been more active. Most of all, I should improve my reading 
comprehension.

The vocabulary difficulty deserves further mentioning because in my interviews two years later with these diarists (as part of a follow-up study), many of them still reported that they had not found an effective way to acquire a "desirable” amount of words and to use the acquired words in an appropriate way in real-life communication. One diarist observed that "English has many different words for the same basic idea" and that "English words tend to be used in different ways". These difficulties were common among junior college students. Most linguistic problems reported above were related to vocabulary difficulty in one way or another.

The fact that students rarely mentioned the difficulties in speaking and writing did not mean that they had fewer troubles with language production. Several reasons for this lack of mention could be suggested: first, writing was not a major component of the syllabus in the first two years and thus was not their immediate concern. Although the influential TEM-4 paper contained a writing component, students found it relatively easy because of its prescribed three-part structure: introduction, text body and conclusion. As for speaking, most students had already survived the period of anxiety in the first year, and were more confident to speak in the second year. Another important reason was the washback effect of TEM-4, in which speaking was not tested.

In summary, students' learning difficulties were not purely concerned with their 
linguistic competence - rather they seemed to be more concerned with the demands that their learning tasks (conditioned by the TEM-4 preparation) placed on their linguistic competence. It is within this context that we shall discuss below students' responses to the linguistic difficulties in their long-term struggles to come to terms with the target language.

\subsection{Responses to the linguistic difficulties}

In exploring the notion of learner beliefs, Benson and Lor (1999) distinguish between quantitative/analytic and qualitative/experiential conceptions of language and language learning (see also comments by Ellis, 2004, p. 542-544). The former involves the conceptualization of a language as a collection of "things" (grammatical concepts, word patterns, etc.) for the learner to accumulate, while the latter involves a conceptualization of a language as an "environment" to which the learner responds. According to Benson and Lor (1999), quantitative and qualitative conceptions are associated respectively with surface and deep approaches to learning. This framework of quantitative-qualitative distinction is found generally useful in analyzing students’ responses to learning difficulties.

As shown in Appendix-2, the students in this study seemed to reveal a predominantly quantitative orientation towards language and language learning, which seemed to be derived from their lack of linguistic competence (note concerns 
that students expressed over poor comprehension, speed and correctness). But as seen later, this quantitative conceptualization of EFL learning as upgrading linguistic competence might be only part of the story.

Students saw vocabulary and speed in language processing as the major obstacles to their language proficiency. Perceptions of other difficulties, such as complicated sentence structures, or decisions over whether to read the questions or the text first in order to achieve a high percentage of correct choices within a time limit also tended to demonstrate their quantitative conceptions of, or approaches to, language learning. In terms of strategy deployment, they recited "useful words, beautiful phrases and beautiful texts ${ }^{5}$, to build up their linguistic competence and to lay a solid foundation for their language learning. The wide range of other strategies employed (miscellaneous mentions in Appendix-2) also demonstrated their quantitative orientation to make sense of language and language learning.

The following entry provided a profile of the learner's mental acceptance of a quantitative approach to language learning:

\section{Extract 3:}

I hated reciting very much. I seldom recited text, and I thought it is useless for my study. Last week, Teacher X [the Intensive Reading teacher of Class X] wanted us recited a text in this week. I had no idea but reciting. From day to night, I recited the text whenever I had time. After a week, I can recite the whole text. Finally I understood what Teacher X did is good for us. Now, I can recognize all of the text word. In my mind, there are dozens of words.

\footnotetext{
${ }^{5}$ As pointed out by one reviewer, students' preoccupation with "beautiful" wording is itself intriguing. While it would need further study, one possibility is that literary traditions within local classroom cultures affect student as well as teacher criteria for effective language use.
} 
Starting from strong resistance to recitation, the diarist finally realized the importance of recitation in enhancing linguistic competence. The mismatch of expectations between the teacher and the learner was apparently resolved and the learner seemed to accept the subject position assigned to him/her by the teacher. Based on my observation, many students held a similar view. Thus we might have the impression that these learners were predominantly quantitatively-oriented, obedient, passive learners. However, we should be cautious in making such claims because there were further insights in other diary entries. Some students clearly expressed the view that recitation was not only "boring" but also "ineffective" because it lacked “an environment for learning things by heart and putting things to communicative use”. Some strongly complained that it was the teacher who forced them to recite, which clearly indicated that recitation might not be the student's natural choice (we should also bear in mind that a majority of diarists did not report using the strategy of recitation). In this case, the gap between teaching and learning was left unattended to:

\section{Extract 4:}

Today Teacher $\mathrm{X}$ asked us to read a text. She said she would ask us to recite it again. When I heard this I felt very upset because of my bad memory.

I didn't like to recite texts when I was a little girl. I thought those texts were so boring. So I often borrowed some interesting books from the library or my classmates. But my teachers often forced us to remember [memorize] the whole texts. I often was afraid of that.

Now Teacher $\mathrm{X}$ asks us to recite the text; it makes me think of the days. I am not object to the way of reciting the text, but I think, although we can recite all the text, we can't use them fluently. 
In the diary data, some students expressed that they needed an external force to push them to learn. The external force could be an examination (e.g. TEM-4), or a course requirement of some sort. The several diarists who were metacognitively aware of the benefits of writing reading reports (Appendix-2) all stated that submitting reading reports as a course requirement forced them to read novels, newspapers and thus had benefited many aspects of their learning. Following Benson and Lor (1999), students' preference to be pushed can be accounted for on the grounds that the object of learning is conceptualized quantitatively in terms of things to be learned and submitted. In my interviews with students, many of them said that their motivation came from one examination after another. This further demonstrated that students' predominantly quantitative conceptions did not originate exclusively from their lack of linguistic proficiency. Based on the diary data, the teacher's classroom behaviours, an examination-oriented educational system, and a lack of environment for language communication, could all account for students' quantitative orientation.

It should be noted that even in undesirable language and education environments students still revealed their qualitative orientation of language learning, which could be seen from their haunting the English Corner to communicate with acquaintances and strangers (for communicative activities in the English Corner on the Chinese university campus, see Huang, 1998), from their searching for opportunities to talk to foreign teachers on campus and to watch English movies to familiarize 
themselves with Western cultures. Although there were limited explicit mentions of these sorts, students seemed to demonstrate their efforts to seek opportunities to learn English in a qualitative way. Viewed from this perspective, the quantitative-qualitative distinction which has proved to be a useful tool in analyzing learners' responses to difficulties is not an either-or, mutually exclusive distinction (Benson, personal communication; see also Ellis, 2004), as the data shows that an orientation towards deep or surface approaches tends to be task- and examination-conditioned and context-specific.

\subsection{Socio-psychological constraints in EFL learning}

In the above section, I have touched upon the notion of classroom role relationships (Wright, 1990) in citing two extracts to illustrate students' different responses to teacher authority (e.g. the non-negotiable command for students to recite texts). Other socio-psychological problems that diarists reported included language anxiety (e.g. examination anxiety), negative self-evaluation of EFL proficiency and slow progress in EFL learning, constraints in independent learning, and resistance to instructional materials chosen by the teacher. In order to examine these problems in relation to specific classrooms and specific teachers' (especially the three teachers of Intensive Reading) classroom behaviours, it might be helpful to outline the distinctive patterns in the diary data of different classes. 


\section{Class $X$ :}

The Class X sample produced no mention of TEM-4 anxiety. Based on my observation as an insider of the institution and informal interviews with students, the probable reasons were: (1) the Intensive Reading teacher, who had been teaching the same course to this class for almost two years, had adequately addressed students' examination concerns in routine teaching; (2) the routine teaching had integrated the preparation for TEM-4 into the regular curriculum; and, (3) the teacher enjoyed a good reputation as a "guarantor of examination success" (Carter, 2002, p. 23). Another distinctive feature of this class was their more frequent use of strategies of isolated recitation (entries/diarists $=21 \% / 29 \%$ ) and contextualized memorization (miscellaneous mentions, Appendix-2), which might be linked to the Intensive Reading teacher's authoritarian classroom behaviour (see Extracts 3-4).

\section{Class Y:}

Recitation (entries/diarists $=14 \% / 21 \%$ ) was less frequently mentioned compared with Class X, but TEM-4 anxiety (entries/diarists $=14 \% / 21 \%$ ) was mentioned only by this class. The probable reason was that students' worries about TEM-4 were not adequately addressed by the Intensive Reading teacher, who was assigned to teach such a class for the first time and was not fully aware of the TEM-4 practices. 


\section{Class Z:}

Class $\mathrm{Z}$ produced the fewest mentions of recitation (entries/diarists $=7 \% / 12 \%$ ) and the most mentions of learning vocabulary in context (entries/diarists = $18 \% / 29 \%$ ), and as in the Class X sample, there was no mention of TEM-4 anxiety. Compared with students in the other two classes, they appeared noisier, less disciplined, less obedient, and perhaps 'lazier" in study. These were my own observations throughout the reading course. Interestingly, Class Z was also the only group in which some members expressed their ideas about independent learning (one possible reason was that the Intensive Reading teacher talked more about this). In the semester of diary-writing (for the Extensive Reading course), Intensive Reading was taught by a young American teacher, who might be less examination-oriented so as to allow for more classroom dynamics. This was confirmed in later interviews and email exchanges with students of this class (e.g. the foreign teacher encouraged students to take turns to teach a text to the whole class, which evolved as a welcome class activity in the English Department).

Bringing together the different contexts of the three classes, we do not have enough evidence to say how far the specific characteristics of the three classes were attributable to the different (Intensive Reading) teachers, but it seems clear that the teachers in the three classes affected the classroom learning processes to some extent and in different ways. 


\section{Summary and conclusion}

Although the diary data appear to indicate that the students' learning difficulties lay mainly with their linguistic competence, a closer scrutiny of the classroom discourse seems to reveal that their linguistic difficulties might be a product of the relationship between their linguistic competence and the demands that examinations (e.g. TEM-4) placed on it. Students' responses to linguistic difficulties were characterized by predominantly quantitative conceptions of, and approaches to, language learning, e.g., efforts to accumulate knowledge and to upgrade language skills through as much practice as possible, recitation and memorization in vocabulary learning, and close attention to precision and details as well as a tendency to study for examinations. This quantitative orientation was not generally problematized but deemed functional by students (and perhaps teachers) in the examination-oriented context. This also seemed to illustrate that the two quantitative-qualitative conceptions of learning might not be mutually exclusive. In our study, learners' option for quantitative approaches to learning was largely due to the examination demands, as well as other socio-psychological constraints which diarists perceived to include undesirable teacher-learner role relationships, negative self-evaluation/self-esteem, TEM-4 anxiety, deficient study skills and learning strategies, and obstacles to independent learning. Although these non-linguistic 
constraints were not frequently mentioned (as many of them were sensitive issues), it could be argued that socio-psychological factors substantially affected learning.

It is hard to predict how far the findings about this group of Chinese tertiary-level students can be generalized to a larger population, but insights from this study should be relatable to similar ethnographic contexts, where students' voices (learning difficulties and immediate concerns) are not well attended to before the implementation of routine classroom practices and teacher-directed innovations (e.g. metacognition training - MT).

Based on the findings, some suggestions could be made for EFL teaching and learning in the general Chinese university setting:

(1) Lack of linguistic competence and pressures from TEM-4 are important but not the exclusive causes of quantitative and surface learning. This surface approach to learning was also attributable to teachers' authoritarian classroom behaviours. Therefore, teachers should negotiate their classroom role relationships with students in order to create a supportive environment for active learning.

(2) Since external force often provides a stimulus for students to learn, we should try to make influential examinations (e.g. TEM-4) work for EFL learning. We might need to integrate routine teaching into the TEM-4 preparation, and yet to minimize simultaneously the potential interference of TEM-4 with the regular curriculum. Here the teacher's attitudes are of great importance in shaping students' conceptions of examinations and regular learning, especially in the Chinese university EFL 
context where the teacher is still often expected to act as an authority to provide exact direction of learning.

(3) Finally, as a reflection on the MT project, this study has suggested that learners’ EFL proficiency, especially the demands that gate-keeping examinations place on limited proficiency, should be taken into account when thinking of launching learner training and in choosing specific language strategies for classroom strategy instruction. For example, in our project, MT might be better regarded if learners had sufficient opportunities to practise cognitive and socio-affective strategies to first address their immediate concerns (linguistic difficulties and important examinations) before they were "suddenly" urged to make sense of the abstract notion of metacognition. Therefore, students' somewhat passive resistance to the pedagogical innovation (i.e. MT for autonomy), as shown by their apparent “non-cooperation” in journal writing (see Section 2), was probably not culturally predisposed. This case study also raised an urgent question to be explored in later learner training studies: how could EFL learners, under examination pressures, really benefit from learner training (especially MT, which might not bring about quick quantifiable results to show both learners and the administration)?

Acknowledgements: I would like to thank Professor Desmond Allison of Carleton University, Canada, Dr. Phil Benson and Professor David Nunan of University of Hong Kong, China for their valuable comments on the earlier versions of this paper. 
Appendices: A summary of important themes in the diary data (total entries/diarists = 84/57: Class $\mathrm{X}=28 / 21$, Class $\mathrm{Y}=28 / 19$, Class $\mathrm{Z}=28 / 17$ ).

1. Perceptions of difficulties and constraints

\begin{tabular}{|l|l|}
\hline $\begin{array}{l}\text { Frequency (Distribution) } \\
\text { Total entries (diarists) }\end{array}$ & Difficulties and Constraints \\
\hline Linguistic dimensions: Total mentions by the three classes \\
\hline $23(20) / 27 \%(35 \%)$ & Limited vocabulary in reading, listening, speaking and writing. \\
\hline $14(13) / \mathbf{1 7 \%}(\mathbf{2 3} \%)$ & Speed in reading or listening. \\
\hline $3(3) / 4 \%(5 \%)$ & Drawing inferences in reading. \\
\hline 4(4)/5\% (7\%) & Decision to read the question or the text first in reading practice. \\
\hline $5(5) / 6 \%(9 \%)$ & Difficulties in reading authentic materials, e.g. novels, newspapers. \\
\hline 2(2)/2\% (4\%) & Complicated sentence structure in reading. \\
\hline Social and psychological dimensions: Total mentions by the three classes \\
\hline 4(4)/5\% (7\%) & Not coming to terms with the teacher-student role relationship. \\
\hline 4(4)/5\% (7\%) & Self-evaluation: no/little improvement in proficiency or a mismatch \\
\hline 3(3)/4\% (5\%) & between great efforts and unexpected outcomes. \\
\hline Social and psychological dimensions: Distinctive themes in Class $Y$ and Class Z only \\
\hline 4(4)/14\%(21\%) Class Y & Anxiety from TEM-4 and other exams. \\
\hline 2(2)/7\%(12\%) Class Z & Constraints in independent learning. \\
\hline
\end{tabular}

\section{Learners' responses to perceived difficulties and constraints}

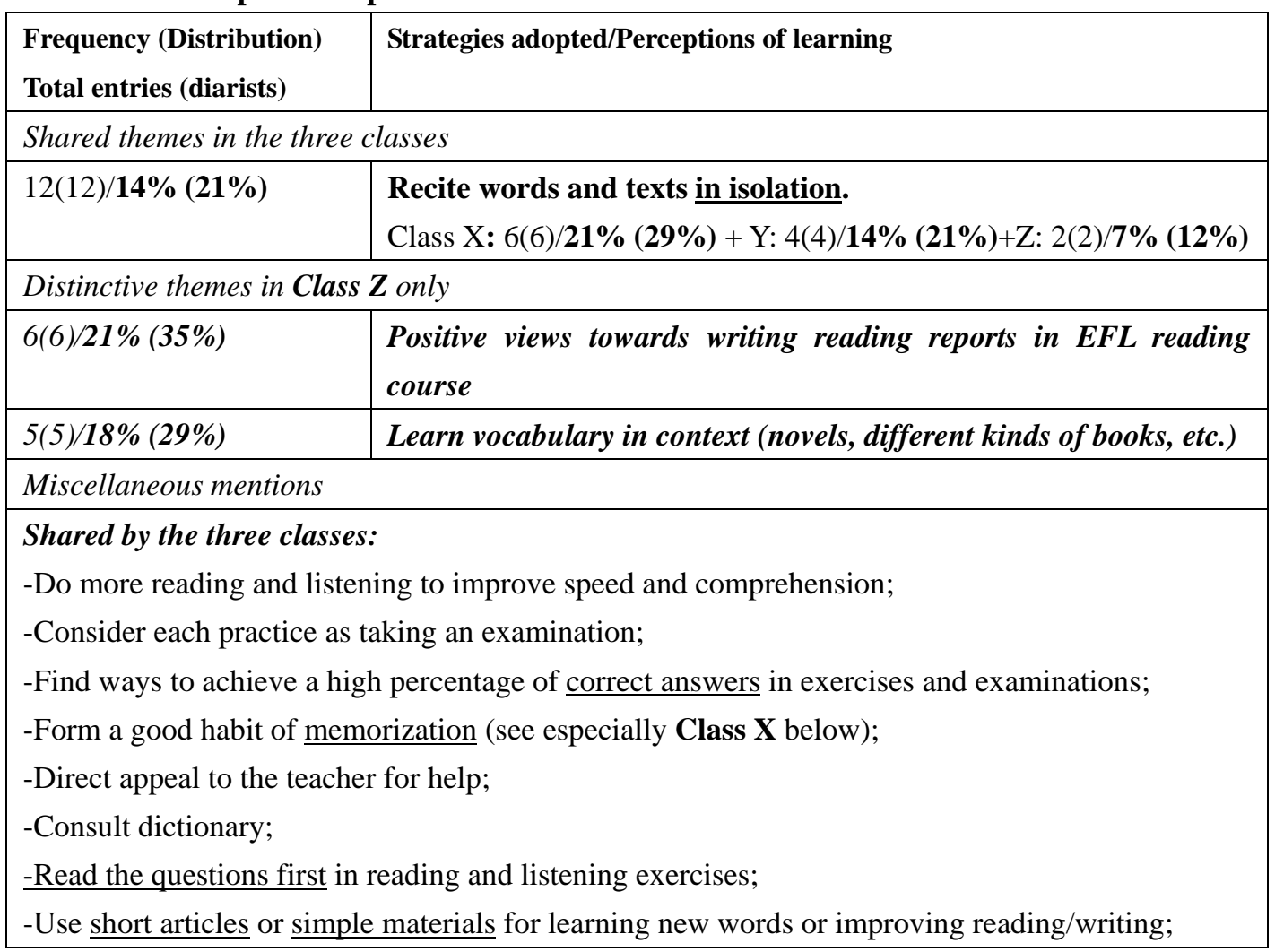


-Read novels and newspapers;

-Recognize the integration of reading with other language skills;

-Go to the English Corner to practise spoken English;

-seek opportunities to talk to foreign teachers on campus;

-Watch English movies to learn the Western cultures;

-Read newspapers to improve spoken English;

-Use computer/internet to learn English.

Reported by a single class:

(Class X)

-Guess word meaning in context;

-Put words in a passage to enhance memorization;

-Group words of the same category to enhance memorization;

-Memorize proper names to enhance listening materials;

-Do exercises and memorize new words;

-Get familiar with the structure of listening texts;

-Ask classmates for advice;

-Realize patience and accumulated knowledge needed for success.

(Class Y)

-Read around a theme in a period of time;

-Recognize the importance of reading in TEM 4;

-Recognize the importance of basic knowledge in TEM 4;

-Recognize the differences between reading in Chinese and reading in English;

-Set time limit for speed reading practice;

-Get to know one's weaknesses and draw up a study plan.

(Class Z)

-Interest in spoken English growing out of a foreign teacher's classroom teaching;

-Speak to oneself to practise spoken English;

-Recognize that English learning is not equal to vocabulary plus grammar;

-Recognize that reading strategies used depend on different contexts and purposes;

-Recognize the benefits of student-teaching in a foreign teacher's class.

\section{References}

Allison, D., 2002. Approaching English Language Research. Singapore University Press, Singapore.

Allwright, R.L., 1984. Why don't learners learn what teachers teach? - The interaction hypothesis. In: Singleton, D.M., Little, D.G. (Eds.), Language Learning in Formal and Informal Contexts. IRAAL, Dublin, Ireland, pp. 3-18.

Bailey, K.M., 1983. Competitiveness and anxiety in second language learning: looking at and through the diary studies. In: Seliger, H.W., Long, M.H. (Eds.), Classroom-oriented Research in Second Language Acquisition. Newbury House, Rowley, Mass, pp. 67-103.

Bailey, K.M., 1991. Diary studies of classroom language learning: the doubting game and the 
believing game. In: Sadtono, E. (Ed.), Language Acquisition and the Second/Foreign Language Classroom (Anthology 28). Regional Language Centre, Singapore, pp. 60-102.

Bailey, K.M., Nunan, D. (Eds), 1996. Voices from the Language Classroom: Qualitative Research in Second Language Classroom. Cambridge University Press, Cambridge.

Benson, P., Lor, W., 1999. Conceptions of language and language learning. System 27, 459-472.

Biggs, J.B., 1987. Student Approaches to Learning and Studying. Australian Council for Educational Research, Hawthorn, Victoria.

Biggs, J.B., 1992. Why and How Do Hong Kong Students Learn? Using the Learning and Study Process Questionnaires (Education Paper No. 14). Faculty of Education, University of Hong Kong.

Biggs, J.B., 1993. What do inventories of students' learning processes really measure? A theoretical review and clarification. British Journal of Educational Psychology 63, 3-19.

Carter, B.A., 2002. Helping learners come of age: learner autonomy in a Caribbean context. Hong Kong Journal of Applied Linguistics 7(2), 20-38.

Cheng, X.T., 2000. Asian students' reticence revisited. System 28, 435-446.

Cortazzi, M., Jin, L.X., 1996a. English language teaching and learning in China (State-of-the-art review). Language Teaching 29, 61-80.

Cortazzi, M., Jin, L.X., 1996b. Cultures of learning: language classrooms in China. In: Coleman, H. (Ed.), Society and the Language Classroom. Cambridge University Press, Cambridge, pp. 169-206.

Ehrman, M.E., 1996. Understanding Second Language Learning Difficulties. Sage Publications, California.

Ellis, R., 2004. Individual differences in second language learning. In: Davies, A., Elder, C. (Eds.), The Handbook of Applied Linguistics. Blackwell, Oxford, pp. 525-551.

Hilleson, M., 1996. “I want to talk with them, but I don't want them to hear”: an introspective study of second-language anxiety in an English-medium school. In: Bailey, K.M., Nunan, D. (Eds.), Voices from the Language Classroom: Qualitative Research in Second Language Education. Cambridge University Press, Cambridge, pp. 248-275.

Hu, G.W., 2002. Potential cultural resistance to pedagogical imports: the case of communicative language teaching in China. Language, Culture and Curriculum 15(2), 93-105.

Huang, J., 1998. English corner and EFL extracurricular writing. English Teaching Forum 36(2), 29-31.

Jin, L.X., Cortazzi, M., 1998. The culture the learner brings: a bridge or a barrier? In: Byram, M., Fleming, M. (Eds.), Language Learning in Intercultural Perspective: Approaches through Drama and Ethnography. Cambridge University Press, Cambridge, pp. 98-118.

Littlewood, W., 1999. Defining and developing autonomy in East Asian contexts. Applied Linguistics 20(1), 71-94.

Littlewood, W., 2000. Do Asian students really want to listen and obey? ELT Journal 54(1), 31-35.

Littlewood, W., 2001. Students' attitudes to classroom English learning: a cross-cultural study. Language Teaching Research 5(1), 3-28.

Liu, N.F., Littlewood, W., 1997. Why do many students appear reluctant to participate in classroom learning discourse? System 25, 371-384. 
McDonough, J., McDonough, S., 1997. Research Methods for English Language Teachers. Arnold, London.

Nunan, D., 1992. Research Methods in Language Learning. Cambridge University Press, Cambridge.

Nunan, D., 1995. Closing the gap between learning and instruction. TESOL Quarterly 29(1), 133-158.

Watkins, D. 1996. Learning theories and approaches to research: a cross-cultural perspective. In: Watkins, D.A., Biggs, J.B. (Eds.), The Chinese Learner: Cultural, Psychological and Contextual Influences. Comparative Education Research Centre, Hong Kong / Australian Council for Educational Research, Victoria, pp. 3-24.

Wenden, A., 1991. Learner Strategies for Learner Autonomy. Prentice Hall, Hemel Hempstead.

Wenden, A.L., 1998. Metacognitive knowledge and language learning. Applied Linguistics 19(4), 515-537.

Wright, T., 1990. Understanding classroom role relationships. In: Richards, J.C., Nunan, D. (Eds.), Second Language Teacher Education. Cambridge University Press, Cambridge, pp. 82-97. 